Open Access

\title{
Self-rated health among elders in different outmigration areas - a case study of rural Anhui, China
}

Weizhen Dong(D)

\author{
Correspondence: weizhen@ \\ uwaterloo.ca \\ University of Waterloo, 200 \\ University Avenue West, Waterloo, \\ Ontario N2L 3G1, Canada
}

\begin{abstract}
China has been a rapid growing economy in recent decades. Part of its economic development engine comes from internal rural-urban migration. The decades-long rural-urban migration is the result of China's long-lasting uneven development between its urban and rural areas and its income and resource distribution inequality. Rural Anhui is one of the most affected outmigration regions of China. The absence of young and middle-aged villagers changed its natural villages' demographics. It broke the self-sufficient rural family structure and their traditional lifestyle with no societal infrastructure to replace family support. Meanwhile, it created aging communities-particularly in relatively poorer villages. This study investigates rural elder villagers' perception of their physical health in the context of rural-urban migration. It explores the reality of the left-behind rural aging population - their real life challenges and regional disparities reflected in their selfrated health status: those who are living in a relatively poorer region (county) tend to have significantly lower self-rated health $(\mathrm{SRH})$ scores than their counterparts in wealthier areas. Women tend to have lower SRH scores than men, and living alone elders tend to perceive their own physical health to be poorer than others. These findings also show that regional economic condition affect individual lives, women are more vulnerable, and healthy personal interaction is an essential element for wellbeing.
\end{abstract}

Keywords: Self-rated health, Elders, Migration, Regional disparity, Rural, China

\section{Introduction}

One of China's major socioeconomic transformations in recent decades is urbanization: rural youth and middle-aged villagers moving to the cities to seek employment opportunity, and a high proportion of them have settled down in urban centers. China had 286.52 million migrant workers in 2017 (National Bureau of Statistics of China 2018), an increase from 274 million at the end of 2015 (National Bureau of Statistics of China 2016). Figure 1 shows China's urbanization trend since the founding of the People's Republic. Anhui Province is one of the major rural migrant-sending regions. ${ }^{1}$ In 2017 , the total number of Anhui migrant workers was 19.2 million, an increase of $2.1 \%$ over 2016, and $66.3 \%$ of them were men; the scale of working abroad in Anhui reached 40,000 people, an increase of 22,000 people over the previous year (Anhui Survey Group of National Statistical Bureau 2018). The large-scale rural-urban migration 


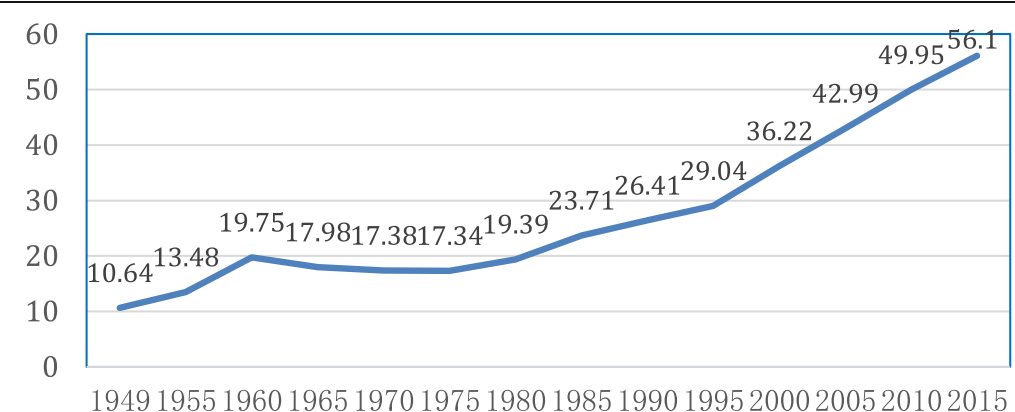

Fig. 1 Urbanization rate of China 1949-2015 (\%). Data source: National Bureau of Statistics (1949-2016), which used National Bureau of Statistics of China 2015 and 2017 data http://data.stats.gov.cn

changed the demographic landscape of both urban and rural China. While quite a number of studies have explored how the rural migrants facing challenges including housing, jobs, and services in the cities (Shi 2008, 2010; Dong 2015; Zhong et al. 2016), few have tackled the issues concerning elders' wellbeing in the migrant-sending regions. In particular, how the impact the outmigration has had on the lives of the parents and grandparents of those migrants-the rural seniors. This study will fill such a gap.

As a high-rate rural-urban outmigration region in China in recent decades, Anhui's rural demographics have transformed dramatically, especially evident are the imbalance of gender and age groups in the villages. The high proportion of elders in rural population causes concerns about senior villagers' wellbeing. In order to assess their physical and mental health, as well as their overall life satisfaction, the indicator self-rated health (SRH) was employed to assess the rural elders' general perception of their physical health and their overall life satisfaction.

\section{Research methods}

This study adopted a mixed methods approach, which involved both qualitative and quantitative research strategies. Face-to-face interview was the main method in qualitative data collection, and survey questionnaire was the main method for quantitative data collection. This study employed multistage stratified cluster sampling strategy. Data collection was done in August 2015 in rural Anhui, in which 12,239 valid survey responses were obtained from 15 villages of three counties. Among them, 1470 of the respondents were 65-years and older elder villagers. These survey data was used for this study. The SRH assessment was categorized into five levels: very good, good, fair, poor, and very poor. Logistic regression models were utilized to analyze the associations between various sociodemographic influence factors and the respondents' SRH scores.

\section{Sample selection}

Step 1: Purposively selected Anhui Province.

Anhui is an inland province of China. It belongs to the East China Economic Zone. Its jurisdiction area covers 140.1 thousand square kilometers, including both well-developed and less-developed regions. At the end of 2017, there were 62.55 
million permanent residents in Anhui. There were 29.75 million living in rural areas, which accounted for $48 \%$ of Anhui's total population. According to the Statistics Bureau of Anhui Province (2018), Anhui had a total of 19.2 million rural out-migrants by the end of 2017.

Step 2: Stratified random sampling of three counties in Anhui based on geographic location and level of wealth.

In order to make sure that the data collected accurately represents the provinces' general status, the province was divided into three regions: Southern, Central, and Northern, and three financial levels: wealthy, average, and poor. The medium counties of the two categories were selected. They are County A, County B, and County C-representing the central, southern, and northern region of Anhui, respectively (see Table 1).

Step 3: Based on the principle of representativeness in terms of geographical location and socioeconomic conditions, a stratified random sampling method was employed. The randomly selected sites were $Y$ and $T$ Townships from County A; $E, P$, and $D$ Townships from County B; and $D$ and $X$ Townships from County $C$.

Step 4: Based on the same principle, a stratified random sampling method was employed in the village selection. Fifteen villages were selected as the sample sites for our survey. All available residents in the selected villages voluntarily participated in the study.

\section{Sample and sample size}

A total number of 12,239 individuals from 15 villages in seven townships of three counties aged 15 and older voluntarily participated in the study's questionnaire survey phase. Most villages achieved full participation. For the purpose of rural elders' self-rated health analysis, the responses of those who were aged 65 and older were selected: $N=1470$.

\section{Data collection methods}

Survey, interview, and focus group discussions were the main data collection methods for this project. In order to ensure data quality, researchers filled out the questionnaires through interviewing each individual respondent and each head of the household. The face-to-face interviews were carried out in locations that were convenient to the interviewees. Participants of the qualitative data collection include villagers, village leaders,

Table 1 Sample counties' basic information

\begin{tabular}{llll}
\hline $\begin{array}{l}\text { County } \\
\text { Indicator }\end{array}$ & $\begin{array}{l}\text { County A } \\
\text { (Central } \\
\text { Anhui) }\end{array}$ & $\begin{array}{l}\text { County B } \\
\text { (Southern } \\
\text { Anhui) }\end{array}$ & $\begin{array}{l}\text { County C } \\
\text { (Northern } \\
\text { Anhui) }\end{array}$ \\
\hline General environment & Good & Very good & Poor \\
Registered residents & 1.2 million & 278 thousand & 1.75 million \\
GDP (¥) & 20.023 billion & 20.42 billion & 16.57 billion \\
GDP/capita (¥) & 16,777 & 67,271 & 9735 \\
Disposable income/capita (¥) & 13,111 & 16,118 & 8410 \\
\hline
\end{tabular}

Source: Statistics Bureau of Anhui Province, 2015 
caregivers, and health and healthcare study experts. Fieldwork conversations were audio recorded with interviewee's consent, and the audio recordings were then transcribed.

Ethics

Since this project involves human subject, a thorough ethics review and clearance on the project's design including the data collection methods were performed and approved by the Ethics Review Committee of the Anhui Medical University.

\section{Measurement}

\section{Dependent variable}

SRH among rural Anhui elders is the dependent variable in this study. SRH was assessed with the question "How do you rate your current health status: very good, good, fairly, poor, or very poor?”

\section{Independent variables}

Demographic characteristics: residence location (County A, County B, and County C); gender (woman/man); and age group (60-64, 65-69, 70-74, 75-79, and $\geq 80$ years)

Chronic disease (diagnosed by a physician): hypertension, diabetes, cataract, cerebrovascular disease, bronchitis, gastroenteritis, cardiovascular disease, asthma, and other (yes/no)

Social security programs enrollment: Medical insurance (yes/no) and old age pension (yes/no)

Household structure: "parents and children," "three generations," "elderly and children," "elderly only," and "other"

\section{Demographics characteristics of the respondents}

The characteristics of the three counties' respondents are as follows: (1) there were more women than men, 57.4\%, 59.6\%, and $63.2 \%$ from County A, County B, and County C, respectively; (2) a high proportion of respondents were elders, $37.3 \%, 32.6 \%$, and $45.3 \%$ from County A, County B, and County C, respectively; (3) a high proportion of respondents were illiterate or received primary school education only; and (4) there is a high prevalence rate of chronic illness. In County B, the wealthiest county of the three, $45.5 \%$ of the respondents had chronic illness; in County A, the rate was $51.1 \%$, and in the poorest county, County $\mathrm{C}$, it was $57.9 \%$ (see Table 2 ).

Hypotheses:

1. Old age, being women, have chronic diseases, have debt, and live with grandchildren affect SRH negatively.

2. Have medical insurance, have old age pension, and live in a wealthier county have positive influence on SRH.

\section{Discussion on elders' self-rated health in Rural Anhui}

Anhui province has contributed many migrant workers to other parts of China, particularly to coastal areas-Zhejiang province 27.53\%, Jiangsu Province $26.34 \%$, and 
Table 2 Descriptive characteristics of respondents in different counties (\%)

\begin{tabular}{|c|c|c|c|c|c|}
\hline Variable & & Total & County A & County B & County $C$ \\
\hline \multirow[t]{2}{*}{ Gender } & Men & 40.3 & 42.6 & 40.4 & 36.8 \\
\hline & Women & 59.7 & 57.4 & 59.6 & 63.2 \\
\hline Age & $65 \sim$ & 24.7 & 37.3 & 32.6 & 45.3 \\
\hline \multirow[t]{5}{*}{ Household structure } & Parents and children & 25.8 & 26.2 & 30.4 & 19.8 \\
\hline & Three generations & 21.4 & 27.3 & 19.5 & 15.2 \\
\hline & Elderly and children & 9.1 & 8.5 & 5.8 & 14.0 \\
\hline & Elderly only & 43.3 & 37.5 & 43.8 & 50.7 \\
\hline & Other & 0.4 & 0.5 & 0.5 & 0.3 \\
\hline \multirow[t]{3}{*}{ Education } & No education & 44.0 & 42.6 & 38.6 & 52.0 \\
\hline & Primary school & 26.5 & 26.0 & 28.0 & 25.6 \\
\hline & Middle school + & 29.5 & 31.3 & 33.4 & 22.4 \\
\hline \multirow[t]{2}{*}{ Occupation } & Farming & 69.0 & 68.5 & 57.0 & 83.5 \\
\hline & Other & 31.0 & 31.5 & 43.0 & 16.5 \\
\hline \multirow[t]{2}{*}{ Chronic disease } & No & 48.8 & 48.9 & 54.5 & 42.1 \\
\hline & Yes & 51.2 & 51.1 & 45.5 & 57.9 \\
\hline \multirow[t]{2}{*}{ Illness within 2 weeks } & No & 54.1 & 62.0 & 58.0 & 40.0 \\
\hline & Yes & 45.1 & 38.0 & 42.0 & 60.0 \\
\hline \multirow[t]{2}{*}{ Hospitalization in past year } & No & 85.0 & 89.0 & 88.3 & 77.5 \\
\hline & Yes & 14.4 & 11.0 & 11.7 & 22.5 \\
\hline \multirow[t]{2}{*}{ Exercise outdoor } & No & 73.9 & 80.3 & 68.4 & 73.4 \\
\hline & Yes & 25.2 & 19.7 & 31.6 & 26.6 \\
\hline \multirow[t]{2}{*}{ Smoke } & No & 79.1 & 78.1 & 78.0 & 83.6 \\
\hline & Yes & 20.3 & 21.9 & 22.0 & 16.4 \\
\hline
\end{tabular}

Shanghai 21.8\% (Statistics Bureau of Anhui Province 2015). Some rural residents also found jobs out of their native villages and townships within the province, or in other countries (Anhui Survey Group of National Statistical Bureau 2018). Population mobility and new employment opportunities provide rural residents different ways of earn a living. Meanwhile, it also changed the affected families' ways of living; especially those migrant workers' left-behind parents and grandparents.

This study found nearly a quarter (24.56\%) of rural Anhui elder respondents reported "poor" or "very poor" health, while $35.24 \%$ of them reported "good" or "very good" health. Considering this group's age and some of them have multiple illnesses or disability, the self-reported health distribution appears to be reasonable (see Table 3). It is not good, however, when compared to a recent study in Shanghai where only $17.4 \%$

Table 3 Anhui Rural Elders' SRH distribution

\begin{tabular}{llc}
\hline & Freq. & Percent \\
\hline Very good & 100 & 6.80 \\
Good & 418 & 28.44 \\
Fair & 591 & 40.20 \\
Poor & 342 & 23.27 \\
Very poor & 19 & 1.29 \\
Total & 1470 & 100 \\
\hline
\end{tabular}


elder respondents from the poorest neighborhood rated their health status as "poor" (Dong et al. 2017).

It is safe to say that rural Anhui and Shanghai have very different socioeconomic environments and they affect peoples' health status differently. A village chief described both "half glass is full" and "half glass is empty" scenario in terms of aging and health-related resources in his village:

We have a Leisure Square and people can dance there. Our village has the largest number of square dancers. We also have an Elderly Activity Center, where there are books, computers, table tennis tables, pool table, indoor fitness equipment, and treadmill, etc. all free of charge. We spent about $¥ 100,000$ for all these last year. The village is responsible for maintenance. The elders can go there for a rest and watch TV. There are 20 beds with duvet like hospitals. There is a staff in charge of the facility.

However, our village's current sports facilities and square dance venues cannot meet the needs of the villagers. The main problem is the lack of outdoor fitness equipment and more standardized entertainment settings. We have one for each residential community now, which is not enough to meet the needs. Some communities really need at least three of them. -QD Village Chief (interview)

Obviously, local resources constrains limited their ability to develop appropriate level of facilities for recreational activities, which in turn affects rural residents' SRH. Besides, other important variables are influencing their SRH as well.

\section{SRH and debt: having debt lowers one's SRH score}

Some elderly peoples' households have debt. The association between debt and SRH is quite interesting. Table 4 shows that while having "no debt" is strongly associated with "good" and "very good" health (38.16\%), a high proportion of them also rated their health status as "poor" or "very poor" (21.55\%).

Only $2.36 \%$ of "have debt" respondents rated their health as "good" or "very good," while $36.49 \%$ of them reported "poor" or "very poor" (see Table 4). This difference is rather substantial, which means socioeconomic position has significant effect on one's SRH.

Table 4 Elders' SRH and debt

\begin{tabular}{llll}
\hline & Have debt & & \\
SRH & Yes & No & Total \\
Very good & 9 & 91 & 100 \\
Good & 61 & 357 & 418 \\
Fair & 118 & 473 & 591 \\
Poor & 101 & 241 & 342 \\
Very poor & 7 & 12 & 19 \\
Total & 296 & 1174 & 1470 \\
\hline
\end{tabular}


Knowing rural households may have debts for house construction or renovation (improving living condition), a look into their medical debt is very necessary. Table 5 shows that among 296 elder respondents reported to have household debt, 159 (53.72\%) have debt due to medical care cost. Among them, nearly equal number of the elders' rated themselves to have "very good" or "good" health $(28.93 \%)$ or "poor" or "very poor" health (30.82\%). The possible explanation is that the medical bill was for other members of their families if the elder respondents are relatively healthy, or the medical care they accessed have restored their health.

Since this group's SRH is poorer than the average ( $30.82 \%$ vs. $24.61 \%$ reported to have poor or very poor), thus, it confirms the hypothesis that having debt lowers one's SRH score.

\section{SRH and economic zone of the county: poorer county associate with lower SRH score}

A county breakdown (see Table 6) shows that elders in different counties have different SRH scores. In the poorest county of the three, County $\mathrm{C}$, where the highest proportion of elder respondents reported poorer SRH scores-rated themselves health status as "poor" (36.92\%), and only about one fifth of them rated their health status to be "good" $(18.46 \%)$ or "very good" (2.23\%).

Since the unit of analysis is "county" here, the social determinants of health are reflected in the SRH of elders residing in different socioeconomic environments. For example, the wealthiest county of the three, County A, has the highest proportion of elders who rated their health status as "very good" and "good" (44.68\%), while the poorest County C has only $20.69 \%$ elders rated their health as "very good" and "good." Meanwhile, 38.14\% elders in County C rated their own health as "poor" and "very poor," but the percentages in County A and County B were $19.03 \%$ and $16.05 \%$, respectively. The differences are substantial. This means a county's overall economic situation has significant impact on elders' SRH. In other words, economic inequality led to health inequality (Venkatapuram et al. 2017).

Regression models in Table 10 also show that the elderly peoples in County $\mathrm{C}$ are more likely to have lower SRH scores than their counterparts in the counties of County A and County B, while there is no significant difference between County A and County $\mathrm{B}$ as they share similar economic status. This confirms that a financially wealthier county has a positive outcome of SRH.

Table 5 Household with medical debt and elders' SRH

\begin{tabular}{llll}
\hline & Medical debt & & \\
SRH & Yes & No & Total \\
Very good & 8 & 1 & 9 \\
Good & 38 & 23 & 62 \\
Fair & 64 & 54 & 119 \\
Poor & 47 & 54 & 101 \\
Very poor & 2 & 5 & 7 \\
Total & 159 & 137 & 296 \\
\hline
\end{tabular}


Table 6 Elders' self-rated health in different counties (\%)

\begin{tabular}{lllll}
\hline & County & & & \\
\cline { 2 - 5 } & County A & County B & County C & Total \\
\hline Very good & 9.08 & 9.14 & 2.23 & 6.80 \\
Good & 35.60 & 30.37 & 18.46 & 28.44 \\
Fair & 36.30 & 44.44 & 41.18 & 40.20 \\
Poor & 17.63 & 14.57 & 36.92 & 23.27 \\
Very poor & 1.40 & 1.48 & 1.22 & 1.29 \\
Total & 100 & 100 & 100 & 100 \\
\hline
\end{tabular}

The SRH has a clear pattern of regional disparity-County A and County B have much better SRH outcomes than those of County $\mathrm{C}$, which is the poorest of the three counties. County $\mathrm{C}$ has the highest illness burden. As the poorest of three counties in the study, County $\mathrm{C}$ shows systemic disadvantage among all (see Table 2). It has the highest percentage of people who are 65 years of age and older: $45.3 \%$ vs. $32.6 \%$ and $37.3 \%$; highest proportion of elders-only households: $50.7 \%$, vs. $37.5 \%$ and $43.8 \%$; highest rate of no formal education residents: $52 \%$ vs. $42.6 \%$ and $38.6 \%$; highest proportion of villagers work on farming: $83.5 \%$ vs. $68.5 \%$ and $57 \%$; highest prevalence rate of chronic illness: $57.9 \%$ vs. $51.1 \%$ and $45.5 \%$; highest percentage of residents had illness within 2 weeks: $60 \%$ vs. $38 \%$ and $42 \%$; and highest hospitalization rate in the past year: $22.5 \%$ vs. $11.0 \%$ and $11.7 \%$. This means that general socioeconomic conditions matter to population's health status. Thus, addressing economic disparity can reduce health inequality.

\section{SRH and gender: women perceive their own health as poorer than men}

As Artazcoz and Rueda states, "In older age groups, the proportion of women is higher than men and increases with advancing age. Therefore, when studying older people, it is essential to study gender as a basis of differentiation"; since "family roles and the persistence of sexual division of domestic work at older ages can be important determinants of health status and gender inequalities in health" Artazcoz and Rueda (2007). It is also true that women are more likely to report poor health status, limitations in mobility, and poor mental health (Rueda et al. 2008). Analyzing gender differences in SRH is certainly crucial.

"Women are sicker, but men die young." This is partly due to women's self-perception of their health-they are more ready to accept their physical health imperfection and fatigue. It is also true in this rural Anhui elders' SRH study: over $41 \%$ of men rated their own health to be good (33.43\%) or very good $(7.91 \%)$, while only about $29 \%$ of women rated their own health to be good $(23.6 \%)$ or very good $(5.73 \%)$ (see Table 7).

More women rated their health condition as poor or very poor $(28.27 \%)$, while a lower percentage of men-about one fifth perceived their own health as poor or very poor. It is true that more men went to the cities to work (see Table 9), which transferred their household responsibilities to left-behind women. Thus, it takes a toll on their health. Just like one of them said: 
Table 7 Gender difference in elders' self-rated health

\begin{tabular}{llll}
\hline SRH & Men & Women & Total \\
\hline Very good & $57(7.91)$ & $43(5.73)$ & $100(6.80)$ \\
Good & $241(33.43)$ & $177(23.60)$ & $418(28.43)$ \\
Fair & $274(38.00)$ & $317(42.27)$ & $591(40.20)$ \\
Poor & $139(19.28)$ & $203(27.07)$ & $342(23.27)$ \\
Very poor & $10(1.39)$ & $9(1.20)$ & $19(1.29)$ \\
Total & 721 & 750 & 1470 \\
\hline
\end{tabular}

I live with my two kids and mother-in-law. Both my father-in-law and my husband are working in the cities. The road condition here is terrible, and it's quite dusty. When it rains, it's almost impossible to walk. I have to take my kids to school and pick them up on a daily bases. It's quite difficult for us. -Wang, A., County C (interview)

The coefficient of rural Anhui elder women's SRH scores is negative, and it is statistically significant when compared with that of elder men's. This indicates the senior women villagers' SRH scores are 2.69 times more likely to be lower than their male counterparts (see Table 10).

This finding confirmed the hypothesis that female gender is negatively correlated with SRH.

\section{SRH and living arrangement: living alone elders perceive their own health as poor}

Prior to economic reform and rural-urban migration, villagers had traditional household structure such as three generations living together or parents living with their children. Rural-urban migration has dramatically transformed the norm of rural households (Dong et al. 2019; Dong and Zhao, 2019), now that elders living alone or with their grandchildren have become normal households. This study found that wealthier regions are relatively better off in this respect than those poorer ones. For example, the wealthiest county, County A, maintained a reasonable proportion of traditional households, although much has been changed as well.

Table 8 Sample counties' demographic factors

\begin{tabular}{|c|c|c|c|}
\hline \multirow[b]{2}{*}{ Factors } & \multicolumn{3}{|l|}{ County } \\
\hline & $\begin{array}{l}\text { County A (Central } \\
\text { Anhui) }\end{array}$ & $\begin{array}{l}\text { County B (Southern } \\
\text { Anhui) }\end{array}$ & $\begin{array}{l}\text { County C (Northern } \\
\text { Anhui) }\end{array}$ \\
\hline Registered residents & 1.20 million & 0.278 million & 1.75 million \\
\hline Agricultural residents (\%) & 86.00 & 76.12 & 80.00 \\
\hline Number of out-migrants & 199,571 & 49,736 & 340,000 \\
\hline Outmigration ratio (\%) & 19.6 & 18.7 & 24.3 \\
\hline Outmigration destinations (\%) & $\begin{array}{l}\text { Another township: } 18.00 \\
\text { Another county: } 1.45 \\
\text { Cities in Anhui: } 18.25 \\
\text { Another province: } 62.30\end{array}$ & $\begin{array}{l}\text { Another county: } 5.60 \\
\text { Cities in Anhui: } 25.17 \\
\text { Another province: } 74.83\end{array}$ & $\begin{array}{l}\text { Another township: } 6.50 \\
\text { Another county: } 4.30 \\
\text { Cities of Anhui: } 5.70 \\
\text { Another province: } 83.50\end{array}$ \\
\hline Out-migrants men (\%) & 50.7 & 58.0 & 56.0 \\
\hline
\end{tabular}


The outmigration gender breakdown in Table 8 shows that a high proportion of out-migrants are men, 50.7\%, 58\%, and 56\% from County A, County B, and County C, respectively. A high proportion of those out-migrants went out of the province of Anhui, $62.3 \%, 74.83 \%$, and $83.5 \%$ from County A, County B, and County C, respectively. A village chief said during the interview

50 percent of our villagers are working elsewhere now. Most of them only come to visit their family and relatives during the Chinese New Year holidays. - Wang, G., County B (interview)

This reality impacts the lives of those who are left behind, most of whom are women, elders, and children. The transformation of household structure and the emergence of non-traditional households are the visible changes in this project's sample sites. Outmigration has impact on all aspects of rural residents' life, and it has become a challenging issue for elderly care in rural China (Wang et al. 2018).

Table 9 shows a detailed household structure counts from the study's sample counties. It shows that elders living by themselves in a household has become a new norm in rural Anhui. County $\mathrm{C}$, the poorest county of the three, has a particularly high proportion of households in which elders are living by themselves-more than a half, or $50.7 \%$. If adding elders living with their grandchildren (14\%), $64.7 \%$ of the households in County $\mathrm{C}$ are non-traditional ones (couples living with their children or three generations living together).

Moreover, "elderly only" has become a dominant household structure in the other two sample counties as well. In County A, it represents $37.5 \%$ of households, and in County B, it represents $43.8 \%$. There is also an emergence of extended family structure, which includes various combinations of extended family and relatives for day-to-day life convenience and practicality.

"Elders-living-with-grandchildren" is another new "normal" household structure now. In County C's sample villages, $14 \%$ of the rural households are elders living with their grandchildren. As one elder participant said:

My wife and I are living with our two grandchildren. Before we had grandchildren, I went to the cities to work. Now our son and daughter-in-law are working in Changzhou (Jiangsu Province), so we are taking care of their children. Our son would send money for cover the expenses when there's an incident or event here. If we needed our son to be here, we'd call him and he'd come home right away. So we are doing fine in general. - Wang, K., County C (interview)

Table 9 Household structures in sample counties (\%)

\begin{tabular}{lllll}
\hline Variables & Total & County A & County B & County C \\
\hline Parents and children & 25.8 & 26.2 & 30.4 & 19.8 \\
Three generations & 21.4 & 27.3 & 19.5 & 15.2 \\
Elderly and children & 9.1 & 8.5 & 5.8 & 14.0 \\
Elderly only & 43.3 & 37.5 & 43.8 & 50.7 \\
Other & 0.4 & 0.5 & 0.5 & 0.3 \\
\hline
\end{tabular}


Although their grandchildren are living without parents and they have to take care of their grandchildren, the elder gentleman Mr. Wang found they are doing well since his son takes care of the expenses and would come home whenever necessary. The overall improved communication and transportation conditions guaranteed the family tie is strong. As what a participant from County A, where $8.5 \%$ of households are "elders living with grandchildren", describes

My son (37 years old) and his wife are working in the city. My wife and I are living with their two children: a girl and a boy. I had been a migrant worker myself years ago. Now if there's anything, we'll make a phone call and our son would come home. - Li, L., County A (interview)

Since Mr. Li himself used to work in the city, he understands the importance of working out of village and is very supportive of his son seeking employment in the city. Although taking care of two grandchildren is quite a heavy responsibility, Mr. Li's son and his wife are a reliable support system, and they would come home when there's a need. Modern communication means also helps the elders feel slightly less stressful. This may be the reason why those elders living with their grandchildren have better self-perceived health, thus better SRH scores.

The cases of Mr. Wang and Mr. Li explained why elders living with grandchildren are more likely to have a higher SRH score than elders living alone. Among all of the household structure types, only the coefficient of "elders living with grandchildren" is significant and has positive effect on their SRH. This finding shows the importance of elders' mental wellbeing on their sense of physical health and overall satisfaction in life.

This finding rejected this study's hypothesis that living with grandchildren has negative effect on elders' health. Instead of childcare burden, as the study's hypothesis implies; the grandchildren assured their close tie with their adult children and their financial security. There are some shortcomings with this kind of living arrangement, however, especially concerning the wellbeing of the children. Some participants have pointed out such issues:

Generally speaking, young children wouldn't receive all preventive immunization until they are six years old. The grandparents tend to forget taking their little ones to get such vaccines during a particular date and time. Thus, many children have missed preventive care under their grandparents' guardianship. Some children are not eating well, either. Children are prone to illness when they eat unhealthy food, which has a great negative effect on their physical health. Also, when it's a busy farming period, grandparents would be working in the fields. Their grandchildren would have no proper food to eat. Sometimes they would eat instant noodles. It's seriously affecting their health.-Shi, L., Hefei (interview)

Those out-migrants left-behind in our village are children and the elderly. It is relatively difficult for them to do manual work. Elders have difficulty help the children with schooling, but they are very good at taking care of their grandchildren's food, housing and transportation. Children usually are emotionally tied with their parents, 
even if their parents only come back to see them once a year, they still feel closer to their parents than their grandparents. It's different family ties: grandparents can take care of their grandchildren, but their grandchildren's relationship with them and their own parents are different.-Qi, H., County C (interview)

Looking at the human environment, we see that children are not living with their parents and old people are not living with their children. The original family structure of rural society has been completely disintegrated. In such a disintegrated state, both the elderly and children are living in a certain distortion. I found the rural elderly suicide a serious problem, which has been the focus of my concern lately.-Li, R., Hefei (interview)

\section{Health status and SRH: elders with chronic diseases perceive their health as poor}

Having physical illness affect one's SRH score negatively is an expected outcome. Regression analysis shows that those elders with chronic diseases are 10.6 times more likely to have poor SRH scores. In other words, the SRH score has significant negative coefficient of "have chronic diseases" (see Table 10).

The elder respondents' chronic diseases prevalence rates in County A, County B, and County $\mathrm{C}$ were $51.1 \%, 45.5 \%$, and $57.9 \%$ respectively. The physical health condition and high prevalence of cancer is of local residents' major concern:

There are lots of cases of stomach cancer and diabetes around here. My father died of cancer. My mother had breast cancer. She lived more than 20 years after her surgery. She died in 2006 when she was 83 years old. We usually go to the village clinic for minor illness, but go to a large hospital for major ones like in Hefei, Shanghai or Beijing. - Zhu, M., County A (interview)

Some participants pointed out that local traditional food such as salt-preserved meat and vegetables maybe the cause of stomach diseases. This means many rural Anhui residents are not well informed about healthy diet and disease prevention. It calls for more active and targeted health promotion and health education at the village level, and in a user-friendly format.

\section{Determinants of rural Anhui elders' SRH}

Regression analysis of this study's survey data found that the older the age, the lower the SRH score; women are more likely to have lower SRH scores; having chronic illness lowers the SRH score; having medical insurance improves the SRH score (but not old age pension, unfortunately); and living in poor region lowers the SRH score (see Table 10).

Multiple regression analyses on elder respondents' self-rated health (Table 10) found that elders' age increase affects SRH negatively. The SRH score of people aged 70-79 years old is significantly worse than that of people aged between 65 and 69. And the people aged 80 years and older have the highest possibility-seven to eight times more likely than other age groups-to have low SRH scores. All three logistic regression models show the coefficient of the age group 65-69 is not significant, but the age 
Table 10 Determinants of rural elders' self-rated health

\begin{tabular}{|c|c|c|c|}
\hline Socio-demographics & M1 & $\mathrm{M} 2$ & M3 \\
\hline \multicolumn{4}{|l|}{ County } \\
\hline County A & - & - & - \\
\hline \multirow[t]{2}{*}{ County B } & -0.658 & -0.206 & -0.408 \\
\hline & $(-0.60)$ & $(-0.18)$ & $(-0.38)$ \\
\hline \multirow[t]{2}{*}{ County C } & $-9.290^{* * *}$ & $-9.032^{* * *}$ & $-8.921^{* * *}$ \\
\hline & $(-8.81)$ & $(-8.47)$ & $(-8.64)$ \\
\hline \multicolumn{4}{|l|}{ Gender } \\
\hline Men & - & - & - \\
\hline \multirow[t]{2}{*}{ Women } & $-2.693^{* *}$ & $-2.695^{* *}$ & $-2.117^{*}$ \\
\hline & $(-3.02)$ & $(-3.02)$ & $(-2.47)$ \\
\hline \multicolumn{4}{|l|}{ Age } \\
\hline $60-64$ & - & - & - \\
\hline \multirow[t]{2}{*}{ 65-69years old } & -1.714 & -1.426 & -1.057 \\
\hline & $(-1.51)$ & $(-1.25)$ & $(-0.97)$ \\
\hline \multirow[t]{2}{*}{ 70-74 years old } & $-5.932^{* * *}$ & $-5.285^{* * *}$ & $-4.242^{* * *}$ \\
\hline & $(-4.72)$ & $(-4.13)$ & $(-3.45)$ \\
\hline \multirow[t]{2}{*}{ 75-79years old } & $-5.161^{* * *}$ & $-4.315^{* *}$ & $-3.773^{* *}$ \\
\hline & $(-3.50)$ & $(-2.87)$ & $(-2.61)$ \\
\hline \multirow[t]{2}{*}{$80+$ years old } & $-8.108^{* * *}$ & $-7.241^{* * *}$ & $-7.277^{* * *}$ \\
\hline & $(-4.07)$ & $(-3.58)$ & $(-3.76)$ \\
\hline \multicolumn{4}{|l|}{ Medical insurance } \\
\hline Have no medical insurance & - & - & - \\
\hline \multirow[t]{2}{*}{ Have Medical insurance } & & $8.403^{*}$ & $10.09^{* *}$ \\
\hline & & $(2.19)$ & $(2.74)$ \\
\hline \multicolumn{4}{|l|}{ Old age pension } \\
\hline Have no old age pension & - & - & - \\
\hline \multirow[t]{2}{*}{ Have old age pension } & & -2.946 & -2.919 \\
\hline & & $(-1.48)$ & $(-1.53)$ \\
\hline \multicolumn{4}{|l|}{ Elders' household structure } \\
\hline Living alone & - & - & - \\
\hline \multirow[t]{2}{*}{ Living with spouse } & & 1.174 & 0.864 \\
\hline & & $(0.77)$ & $(0.59)$ \\
\hline \multirow[t]{2}{*}{ Living with grandchildren } & & $4.356^{*}$ & 3.307 \\
\hline & & $(2.21)$ & $(1.75)$ \\
\hline \multirow[t]{2}{*}{ Living with children } & & 0.812 & -0.824 \\
\hline & & $(0.36)$ & $(-0.38)$ \\
\hline \multirow[t]{2}{*}{ Three generations living together } & & 2.434 & 1.144 \\
\hline & & $(1.33)$ & $(0.65)$ \\
\hline \multicolumn{4}{|l|}{ Chronic illness } \\
\hline Have no chronic diseases & - & - & - \\
\hline \multirow[t]{2}{*}{ Have chronic diseases } & & & $-10.60^{* * *}$ \\
\hline & & & $(11.54)$ \\
\hline \multirow[t]{2}{*}{ Constant } & $72.90^{* * *}$ & $70.69^{* * *}$ & $67.22^{* * *}$ \\
\hline & $(70.25)$ & $(38.63)$ & $(37.75)$ \\
\hline
\end{tabular}


Table 10 Determinants of rural elders' self-rated health (Continued)

\begin{tabular}{clll}
\hline Socio-demographics & M1 & M2 & M3 \\
\hline$N$ & 1525 & 1525 & 1525 \\
$R^{2}$ & 0.0859 & 0.0933 & 0.1668 \\
\hline
\end{tabular}

$t$ statistics in parentheses

${ }^{*} p<0.05,{ }^{* *} p<0.01,{ }^{* * *} p<0.001$

groups over 70 are significantly negatively associated with SRH. This indicates that elders' self-perceived health status decline after age 70, and even more so after age 80 .

In terms of social security variables, the positive influence of "having medical insurance" on SRH is expected, but "having pension" does not have the same effect, which is likely due to the insignificant amount of money involved in the pension plan. The pension, merely around $¥ 100$ per month, does not make a meaningful difference in the elders' lives.

We had a survey on rural residents' pension recently. Those who are 65 years of age or older could receive $¥ 75$ per month initially. This year, some regions had increased their pension level. In County (B), it’s ¥90 per month now. —Lou, Y., Hefei (interview).

Pension is a relatively new concept in rural China. Until recently, rural residents had no pension. Anhui started a pilot pension plan in 2009 in $10 \%$ of its counties. In the most recent 2017 Anhui Province Policy on New Rural Social Pension Subsidies' Standard, the government has implemented an old age insurance scheme for rural residents.

In terms of village level medical care, a village doctor in County B says that only two staff are responsible for the health of the 4036 residents in the village. He usually sees over 20 fellow villager-patients per day. He said:

The basic medication was not delivered in time. We simply don't have any cheap drugs now. It seems the cheaper the drugs, the less willing they will be to deliver. Maybe because the profit level is too low, the pharmaceutical manufacturer is unwilling to produce and deliver such essential drugs. Now the prices of commonly used medicines have risen. Originally, the prices of some drugs was within a few Jiao ( 1 Jiao $=0.1$ Yuan), now they are more than ten Yuan, and some of the prices have increased to an unbelievably high level. Interestingly, the more expensive the medicines are, the sooner they would be delivered to us. So the cost for our villagers to see a doctor is much higher now than before. Our villagers don't farm and do less physical exercise now. Chronic diseases and malignant tumors are increasingly prevalent. Too bad, our clinic has no equipment for blood lipid and blood sugar tests. For physical examination, we can only take our patients' blood pressure, height and weight. There is also no tap water, no tap water in our clinic's toilet. -Zhao, Y., County B (interview)

Village clinic's condition sounds problematic. Village doctors are supposed to be the gatekeepers in rural areas, but they are most likely to be substandard healthcare workers, and not well-paid nor well-equipped. Meanwhile, they have heavy healthcare burden even just count aging factor alone. 
Our village's total population is about 5000 . The aging population accounts for nearly $75 \%$, we have many elderly people. Over $30 \%$ of our villagers left for work in the cities.-Tang, L., County C (interview)

Village doctors are usually trained in vocational schools. Their role is a gatekeeper and public health implementer at the grassroots level. Currently, the village doctors are like self-employed entrepreneurs with a legitimate license to practice medicine and they practice medicine under the guidance of government policy and village leadership. They not only do not have sufficient income, they also do not have proper social insurance packages, although they are responsible for thousands of local residents' health. The limited healthcare resources and other conditions all pose challenges to village doctors.

\section{Conclusion and policy recommendations}

The findings of this study proved most of our hypotheses. In terms of gender, women's SRH overall score is significantly lower than that of men. On age, people aged 70-79 years old got worse SRH than that of people aged between 60 and 69, and the people aged 80 years and over have the lowest SRH scores. Physical health illness affect SRH negatively, those who have chronic diseases decreases the SRH score. Having medical insurance increases the SRH score. The coefficient of "have medical insurance" is significantly positive. And regional economic status affects local residents' SRH-the poorer the region, the lower the SRH score.

Two of the findings rejected the study's hypotheses. Firstly, enrolment to old age pension program has no effect on respondents' SRH, which shows the current pension level is fairly insignificant. The pension amount needs to be increased in order to have any positive influence to the seniors' quality of life. Secondly, living with grandchildren helps the elders to have better SRH score. Among all living arrangements or household structure, only the coefficient of "living with grandchildren" is significant and has a positive effect. Instead of childcare burden, those elders who live with their grandchildren have better self-rated health than their peers. This proves the importance of family interaction. On the one hand, the elders' out-migrant adult children are more likely to have frequent communications with them for staying in touch with their children and provide financial support for their left-behind family; on the other hand, the responsibility of caring for grandchildren may have added meaning and purpose to the elders' lives.

Rural residents in China used to live in a self-sufficient traditional life for centuries. Prior to rural-urban migration, each household was able to take care of their own affairs, including raising their own children and taking care of their elders. Once the working age villagers left home for working in cities, many households faced challenges in their day-to-day life. It is particularly true since there is no societal infrastructure for the families to rely on and to support the household structure's transformation. The findings of this rural Anhui elders' SRH study informed us that there is an urgent need for filling the gaps. In other words, supporting mechanisms for Anhui villagers' wellbeing require special attention. Specifically, elders in rural areas need equal access to various social services and reasonable eldercare facilities like their urban counterparts. 
The findings of this study suggest that general economic environment and societal factors affect the elders' SRH and their overall life satisfaction. Rural elders' health issue requires urgent attention from different levels of government. Policymakers need to find ways to (1) improve rural villagers' living condition and their health status through regional economic development; (2) develop facilities and services for meeting the rural residents' needs; and (3) provide means for health promotional activities.

\section{Strategies on improving rural elders' social support system}

Anhui rural elders' SRH in this study shows that socioeconomic status, geographical location, and living arrangements have all impacted their perception of physical health. Found out the influence factors on the elders' SRH proves the existing gaps. This provides us the opportunity to develop effective measures to improve the rural elders' quality of life. Currently, there is a severe lack of infrastructure for elders' socialization and day-to-day life services, including healthcare, at the village level. Only when this gap is closing in, the rural elders' quality of life will be improved. The following are the areas that require special attention.

\section{Elder service}

Establish elder living assistance service network at the village level: Elders need access to daily living assistance such as meals, house cleaning, shower, and other essential services. Health-promotion activities should be organized, and villagers encouraged to participate in physical exercises and learn health-related knowledge, especially about illness and injury prevention and self-care. Also important is to train social workers who can motivate rural elders to participate in various recreational activities that enhance villagers' interactions.

\section{Eldercare facility}

Setup eldercare facility in villages that can provide accessible eldercare beds: Village doctors can provide regular medical checkup and basic healthcare to the elders as well as other villagers. This requires the strengthening of village level healthcare capacity, which includes human resources and necessary medical care supply.

\section{Neighborhood support network}

Some villages have acted on initiatives that can cope with the aging reality of their villagers, including the establishment of a neighborhood support network, although implementation of such initiatives still face challenges. As a villager said:

We have an idea of setting up a Safety Guard network, ten neighbouring households as a group-network. For example, if an elderly person is living alone experiencing sickness or facing an emergency situation, s/he can press a quick-dial key on the cell phone, and everyone in the group-network would be alerted and can come to help out. It is not fully functional yet, since not many know how to operate the system properly.-Wang, M., County B (interview)

\section{Healthy environment}

Improve the physical environment of the villages: For the benefits of rural residents' health, improving local air quality, water quality, and road accessibility are very 
important. Only when these basic conditions are being met, rural residents' wellbeing, particularly the elders and the children, would be possible.

\section{Social security}

Formulate evidence-based social policy for addressing rural elders' day-to-day life needs: The most pressing issues include but not limited to (1) increase pension level to minimum living cost and (2) improve healthcare insurance's financial protection function and reduce the burden of disease in rural China.

\section{Endnotes}

${ }^{1}$ Other main migrants-sending provinces are: Henan, Hubei, and Sichuan

\section{Abbreviations}

GDP: Gross domestic product; SRH: Self-rated health

\section{Acknowledgements}

The author is grateful to the Lupina Foundation of Canada for its vision and financial support to this project. The author is appreciative of Dean and Professor Qicheng Jiang's Anhui Medical University research team for its excellent work. The author is also thankful to the two reviewers for their constructive suggestions and comments to the earlier version of this paper.

\section{Funding}

This project is sponsored by the Lupina Foundation of Canada, which actively supports scholarly activities that takes social determinants of health perspective and with innovative approaches.

\section{Availability of data and materials}

The data used for this paper's analysis is available.

\section{Authors' contributions}

The author designed the study and wrote the article. The author read and approved the final manuscript.

\section{Competing interests}

The author declares that she has no competing interests.

\section{Publisher's Note}

Springer Nature remains neutral with regard to jurisdictional claims in published maps and institutional affiliations.

Received: 26 November 2018 Accepted: 7 May 2019

Published online: 02 July 2019

\section{References}

Anhui Survey Group of National Statistical Bureau. 2018. "New phenomenon of migrant workers' mobility in our province in 2017". http://www.ahdc.gov.cn/

Artazcoz, L., and S. Rueda. 2007. Social inequalities in health among the elderly: A challenge for public health research. Journal of Epidemiology \& Community Health 61: 466-467.

Dong, W., J. Wan, Y. Xu, C. Chen, G. Bai, L. Fang, A. Sun, Y. Yang, and Y. Wang. 2017. Determinants of self-rated health among shanghai elders: a cross-sectional study. Bmc Public Health 17 (1): 807. https://doi.org/10.1186/ s12889-017-4718-5.

Dong, W., and C. Zhao. 2019. Population mobility and migration policy. In Social Policy in China: from State-led to Market-led Economy, ed. W. Dong. Rock's Mill Press.

Dong, Weizhen. 2015. Migrant workers' healthcare challenge and workplace intervention strategy. In American Review of China Studies Fall Issue.

Dong, W., Qicheng, J., Shanfa, Y., Lidan, W., and Zehan, P. (2019). "Healthcare Policy in Rural China" in Weizhen Dong (ed) Social Policy in China: From State-led to Market-led Economy. Rock's Mills Press.

National Bureau of Statistics of China. 2015. National Monitoring and Survey Report on Rural Migrant Workers in China in 2014《2014年全国农民工监测调查报告》http://www.stats.gov.cn/tjsj/zxfb/201504/t20150429_797821.html

National Bureau of Statistics of China. 2016. Monitoring and Survey Report on Rural Migrant Workers in 2015《2015年农民工 监测调查报告》http://www.stats.gov.cn/tjjj/zxfb/201704/t20170428_1489334.html

National Bureau of Statistics of China. 2017. Monitoring and Survey Report on Migrant Workers in 2016《2016年农民工监测 调查报告》http://www.stats.gov.cn/tjsj/zxfb/201704/t20170428_1489334.html

National Bureau of Statistics of China. 2018. Monitoring and Survey Report on Migrant Workers in 2017《2017年农民工监测 调查报告》http://www.stats.gov.cn/tjsj/zxfb/201804/t20180427_1596389.html

Rueda, S., L. Artazcoz, and V. Navarro. 2008. Health inequalities among the elderly in western Europe. Journal of Epidemiology \& Community Health 62: 492-498. 
Shi, L. 2008. "Rural migrant workers in China: scenario, challenges and public policy," ILO Working Papers 994204063402676 , International Labour Organization.

Shi, L. 2010. The economic situation of rural migrant workers in China. China Perspectives 2010 (4).

Statistics Bureau of Anhui Province. 2015. Anhui Population. Government website http://www.ahtj.gov.cn/tjwweb/web/index.jsp

Statistics Bureau of Anhui Province. 2018. Anhui Population. Government website http://www.ahtj.gov.cn/tjjweb/web/index.jsp

Venkatapuram, Sridhar, Hans-Jörg Ehni, and Abha Saxena. 2017. Equity and healthy ageing. Bulletin World Health Organization 95: 791-792.

Wang, Lidan, Weizhen Dong, Yunqing Ou, Shuting Chen, Jingjing Chen, and Qicheng Jiang. 2018. Regional differences and determinants of self-rated health in a lower middle income rural Society of China. International Journal for Equity in Health 17: 162.

Zhong, Bao-Liang, Tie-Bang Liu, Jian-Xing Huang, Helene H. Fung, Sandra S.M. Chan, Yeates Conwell, and Helen F.K. Chiu. 2016. Acculturative stress of Chinese rural-to-urban migrant workers: a qualitative study. PLoS One 11 (6).

Submit your manuscript to a SpringerOpen ${ }^{\circ}$ journal and benefit from:

- Convenient online submission

- Rigorous peer review

Open access: articles freely available online

- High visibility within the field

- Retaining the copyright to your article

Submit your next manuscript at $\boldsymbol{\nabla}$ springeropen.com 